\title{
Triazolam Impairs Avoidance Reaction-A Scientific Proof Why the Victim does not Escape from Drug-Facilitated Sexual Assaults
}

\author{
Keiko Shimizu ${ }^{1^{*}}$, Tomohiro Ohmura ${ }^{2}$, Katsuhiro Okuda ${ }^{1}$, Masaru Asari ${ }^{2}$, Hiroshi Shiono ${ }^{1}$ and Kazuo Matsubara ${ }^{2}$ \\ ${ }^{1}$ Department of Legal Medicine, Asahikawa Medical University, Midorigaoka-Higashi, Asahikawa, Japan \\ ${ }^{2}$ Department of Clinical Pharmacology \& Therapeutics, Kyoto University Hospital, Sakyo-ku, Kyoto, Japan
}

"Corresponding author: Keiko Shimizu, Department of Legal Medicine, Asahikawa Medical University, Midorigaoka Higashi 2-1-1-1, Asahikawa 078-8510, Japan, Tel: 81166 682433; Fax: 81166 682439; E-mail: okeichan@asahikawa-med.ac.jp

Received date: Mar 8, 2016; Accepted date: Jul 6, 2016; Published date: Jul 13, 2016

Copyright: $\odot 2016$ Shimizu K, et al. This is an open-access article distributed under the terms of the Creative Commons Attribution License, which permits unrestricted use, distribution, and reproduction in any medium, provided the original author and source are credited.

\begin{abstract}
Following closely behind levels in Western countries, the number of drug-facilitated sexual assaults (DFSAs), involving the illicit use of medicine, has been recently increasing in Japan. Tirazolam is the most frequently used date-rape drug in DFSAs occurring in Japan. In this study, the effect of triazolam on behavior in response to fear and anxiety was evaluated using an elevated plus-maze test in mice. Triazolam-treated animals $(0.01 \mathrm{mg} / \mathrm{kg})$ showed no significant difference in total locomotor activity compared with vehicle-treated mice (controls). On the contrary, activity levels on the open arms of the apparatus (time spent, mean value of movement), where mice would normally feel anxiety or fear, were significantly increased in triazolam-treated mice compared with controls. However, total locomotor activities on the plus-maze were not different between two groups, indicating that sedation was not induced by tirazolam under these conditions. These results suggest that triazolam treatment led the mice to become insensitive to fear and anxiety; their defence reactions were impaired. We conclude that this finding provides scientific evidence in reply to defence arguments presented in court trials that there is little or no evidence of the victim attempting to escape from a sexual assault. Additionally, the finding is as true of other benzodiazepine receptor agonists as of triazolam.
\end{abstract}

Keywords: Drug-facilitated sexual assaults (DFSAs); Date-rape drug; Elevated plus-maze test; Triazolam; Avoidance reaction

\section{Introduction}

Since the mid-1990s, there has been a steady increase in the number of crimes, including sexual assaults, in which victims were unwittingly led to consume alcohol pretreated with hypnotics (or tranquilizing agents) and/or anxiolytics (both are benzodiazepine receptor agonists) in Japan [1-3].

When chemicals including prescribed medicines are used to incapacitate someone for the purposes of committing drug-facilitated sexual assaults (DFSAs), these drugs are defined as "date-rape drugs", also referred to as "predator drugs" or "club drugs" [4-9].

In the United States of America, flunitrazepam (Rohypnol ${ }^{\circledR}$, ketamine, and gamma-hydroxybutyrate $(\gamma-\mathrm{GHB})$ are commonly used date-rape drugs [10-16]. These drugs, including benzodiazepine receptor agonists, are all odourless and colourless, and can easily be concealed in beverages, incapacitate humans and render the victims vulnerable to DFSAs.

The physical symptoms and signs of DSFA victims attributable to the pharmacological actions of benzodiazepine receptor agonists may cause loss of consciousness (due to the hypnotic effect), decrease in muscular strength, and staggering (due to the muscle relaxant effect), loss of caution and error in judgment (due to anxiolytic effect), and loss of memory with anterograde amnesia.

Therefore, victims are unaware of and unable to recollect events that happened after being drugged. These are high-risk drugs when combined with alcohol, although alcohol alone has been and is still the drug most commonly associated with sexual assaults.

The Japanese legal system in facie curiae is often unable to comprehend or accept the anterograde amnesia in DFSA victims as prima facie evidence, because the assault, if it did actually occur, would be considered to have left a clear and indelible impression upon the victim.

We have previously reported that anterograde amnesia frequently occurs after taking benzodiazepines and ethanol in a rat model [17]. In that investigation, we studied in vivo hippocampal presynaptic glutamate transmission in conjunction with memory deficits induced by benzodiazepines and ethanol in rats as an animal model of amnesia, and found that significant decreases in hippocampal glutamate transmission closely correlated with the extent of impairment of spatial memory performance.

The purpose of the present study using a rodent model was to establish scientific evidence that a loss of danger avoidance performance, which is often observed in DFSAs, is indeed a psychoactive effect of benzodiazepine receptor agonists.

\section{Materials and Methods}

\section{Materials}

Triazolam, which was tested as a typical benzodiazepine receptor agonist in this study, was commercially acquired from Pfizer Co. Ltd. (Tokyo, Japan). All other chemicals were of reagent grade, and were from Wako (Osaka, Japan). The drug was dissolved in physiological 
saline $(1 \mu \mathrm{g} / \mathrm{mL})$ with ultrasonication for $30 \mathrm{~min}$ before the experiment. Saline was used as the vehicle.

\section{Animal treatment}

The present experiment was approved by the Ethical Committee for Appropriate Animal Experiments at Asahikawa Medical University and was performed in compliance with the Japanese Experimental Animal Guidelines.

Female BALB/c mice (19-20 weeks old) weighing $30 \mathrm{~g}$ to $35 \mathrm{~g}$ (SLC, Shizuoka, Japan) were housed in stainless-steel cages at 6 mice/cage $(17 \mathrm{~cm} \times 30 \mathrm{~cm} \times 10 \mathrm{~cm})$ for at least 1 week prior to behavioural testing. Animals were given standard commercial food pellets (Oriental Yeast Co. Ltd., Tokyo, Japan) and water ad libitum, and were accommodated in a temperature-controlled room $\left(24 \pm 1^{\circ} \mathrm{C}\right)$ maintained on an alternating $12 \mathrm{~h}$ light/dark cycle (lights off at 07:00). Behavioural tests were performed during the dark phase of the light cycle (09:00 to 12:00).

To evaluate the anxiety-related behavior in crisis situation, two groups of mice were subjected to the elevated plus-maze test. Mice were intraperitoneally administered with triazolam at $0.01 \mathrm{mg} / \mathrm{kg}$, in a volume of $10 \mathrm{~mL} / \mathrm{kg}$ of body weight (experimental group, $\mathrm{n}=7$ ), or with the same volume of sterile saline (control group, $n=7$ ) 10 min before the elevated plus-maze test.

\section{Evaluation of anxiolytic effects of triazolam in response to crisis situations}

The elevated plus-maze test, which has been successfully used for the screening of potential anxiolytics, has previously been described [18-26]. The explanation of the behavior of rodents in the elevated maze is that exposure to novel stimuli (in the form of maze arms) can evoke both exploratory and fear-driven tendencies, thus generating approach-avoidance conflict behavior, and the elevated maze arms evoke a greater level of fear in the open arms (and therefore more avoidance behavior) than enclosed arms [18]. Briefly, the elevated plus-maze consists of two open $(25 \mathrm{~cm} \times 5.6 \mathrm{~cm} \times 0.5 \mathrm{~cm})$ and two closed $(25 \mathrm{~cm} \times 5.6 \mathrm{~cm} \times 20 \mathrm{~cm})$ arm emanating from a common central arena $(4.2 \mathrm{~cm} \times 4.2 \mathrm{~cm})$ to form a plus shape (Figure 1).

Fig. 1

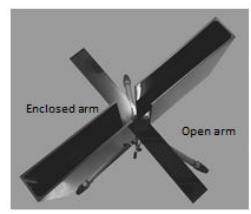

Figure 1: A diagram of the elevated plus-maze placed on the floor was used for testing mice.

The entire apparatus was set $40 \mathrm{~cm}$ above the floor level. First, a mouse was placed on the central arena of the maze facing an open arm and its movement was recorded by an instrumentation system with laser sensors (PLUS MAZE PM-20, MELQUEST Co., Ltd., Toyama,
Japan) at $10 \mathrm{~min}$ intervals. For the purpose of analysis, three measurements were taken as performance indexes: open-arm activity (time spent in the open arms relative to the total time spent in the maze: open/total $\times 100$ ), mean value of movement (counts of beam breaks on the maze in each arm), and number of entries into the open arms relative to the total number of entries into any arm (open/total $\times$ 100). Locomotor activity was expressed as the number of total arm crossings (entries central arena) and the total value of movement in the maze. Performance indexes of open-arm activity were used to evaluate the anxiolytic effect.

\section{Statistical Analysis}

All of the data were expressed as the mean \pm SEM. Differences between the treated mice and control mice were determined with the Student's t-comparison test. Differences with a $\mathrm{P}$ value of $<0.05$ were regarded as statistically significant.

\section{Results}
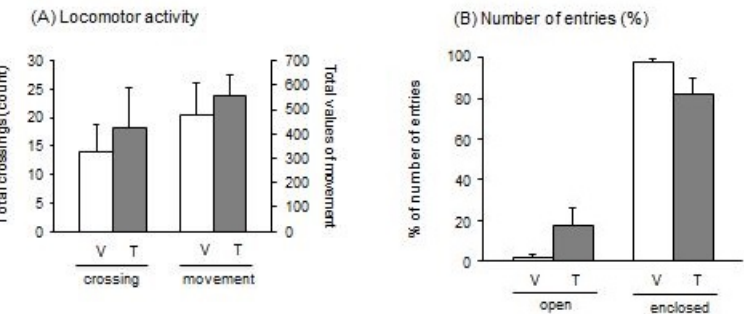

(C) Time spent in each arm
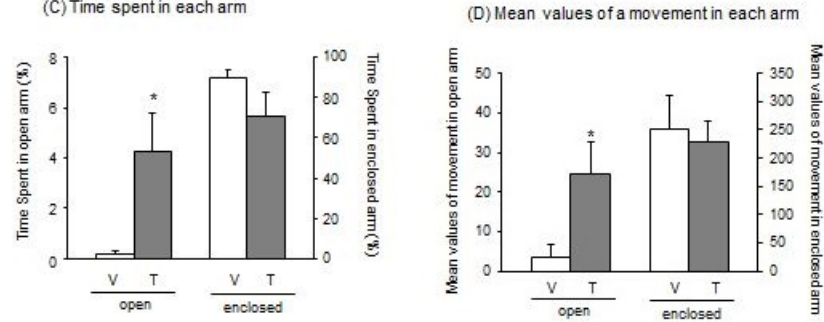

Figure 2: Effect of triazolam (T) on anxiolytic behavior in the elevated plus-maze test of mice compared with vehicle (V) use. Columns and vertical bars represent the means \pm SEM. $(n=7)$. Each mouse was allowed to freely explore the maze for $10 \mathrm{~min}$. Triazolam or vehicle was intraperitoneally administered $10 \mathrm{~min}$ prior to the maze test. Differences where ${ }^{\star} \mathrm{P}<0.05$ were significantly different from values of the vehicle-treated group.

Locomotor activities, evaluated by total number of crossings and the total value of movement, were not influenced by the treatment with triazolam (Figure 2A).

However, activities in the open arms, which were evaluated as time spent and mean value of movement, were affected by the treatment of triazolam. The time spent in the open arms was significantly $(\mathrm{P}<0.05)$ longer in triazolam-treated mice $(4.2 \pm 1.6 \%$ of total time on the maze) than controls $(0.2 \pm 0.2 \%)$ (Figure $2 \mathrm{C}$ ).

The mean value of movement in the open arm also markedly ( $\mathrm{P}$ $<0.05)$ increased in triazolam-treated mice $(24.4 \pm 8.15 / 10 \mathrm{~min})$ compared with controls $(0.2 \pm 0.2 / 10 \mathrm{~min})$ (Figure $2 \mathrm{D})$. The number 
of entries into open arm was slightly increased by triazolam treatment, and performance indexes of closed-arm activity were not significantly different between the two groups (Figures 2B-D).

\section{Discussion}

In 1995, we were asked to provide our medical perspective by a prosecutor regarding a particular crime case: After meeting on the street, two males (a rental video shop owner and an office worker) coaxed a female high school student to a karaoke bar, where she unwittingly took a tiazolam $(0.25 \mathrm{mg})$ pretreated cola prepared by the perpetrators. The victim was stupefied and rendered unconscious after consuming the triazolam-pretreated beverage, and the two males sexually assaulted her, and illegally shot a video of the assault with the intention of selling it on the black market. Since the investigating authorities, though aware that she had unintentionally consumed triazolam, were unable to comprehend how the victim could have no recollection of the event after being subjected to such a significant assault, an inquiry was made to our department concerning the pharmacological effects of triazolam. We confirmed that her symptoms resembled "anterograde amnesia" which was manifested as a side effect of triazolam intake [27-29], viz., the victim was under the influence of the drug and was unable to form memories of events at the time when the crime was committed.

After our experience in this case, we re-created those symptoms in an experimental animal model, and revealed a neuropharmacological mechanism of anterograde amnesia induced by alcohol combined with triazolam. In this animal model, we employed the Morris water maze test combined with the brain microdialysis technique to verify anterograde amnesia produced by alcohol combined with benzodiazepines. This combination of neurodepressive agents specifically reduces neural transmission of glutamate in the dorsal hippocampal sites, thus inhibiting spatial memory formation to induce anterograde amnesia [17]. These findings strongly support that claims of anterograde amnesia due to triazolam action by victims are not fabrications or false impressions, but are in fact verified behaviorally, pharmacologically, and neurologically. We have subsequently been summoned as witnesses in many criminal trials of similar cases, and have used the findings from that study as a reference [1].

In these cases, another question about the plaintiff's behavior often arose: viz., why was there little or no evidence of the plaintiff attempting to escape from the perpetrators' assault? The obvious reason was that the plaintiff was rendered passive and incapacitated due to the drug effects i.e., unable to put up resistance due to being drugged. Misinterpretation and incomprehension of, and failure to recognize this behavior by the court often led to inappropriate judgments, in which the sexual activity was considered to have been consensual and feigning ignorance on the part of the plaintiff reigned. These judgments thus led to the actual victim further unacceptable and unbearable suffering. As such, scientific evidence in support of the victim's loss of defenses during the sexual assault was desperately needed.

The elevated plus-maze is widely used as a behavioral assay for rodents, and it has been confirmed as reliable of measuring the anxiolytic effects of pharmacologically active agents and has helped to define the mechanisms underlying anxiety-related behavior. Because placing a rodent on an elevated fenceless open arm is actually inducing a crisis situation or fear for the rodent, and where the anxious behavior is reflected by decreased locomotor activity in the open arm (duration and/or number of entries) and vice versa [18-26]. In nature, rodents prefer dark enclosed spaces (it is the enclosed arm in this case) with walls to open areas. Therefore, the elevated plus- maze is a useful model to study crisis-ignoring behavior, such as lack of flight-and/orfight response, in DFSA cases.

This experimental animal model, where arbitrary motion could not be controlled by the investigator, clearly demonstrated that insensitivity to fear and/or crisis was induced as a result of the anxiolytic effects typically elicited by benzodiazepine receptor agonists, such as triazolam. In fact, since the open arms of the plus-maze represent a crisis or danger zone for the animals, locomotor activity in the open arms was significantly $(\mathrm{P}<0.05)$ less than that in the closed arms in control rats. On the contrary, open-arm activity increased significantly $(\mathrm{P}<0.05)$ as a result of triazolam administration. However, total locomotor activity in the danger zone did not decrease in the triazolam-treated group as compared with the control group in this experimental condition, indicating that there was no reduction in motor activity due to the sedative effect induced by the administered drug in the present concentration. These experimental findings are consistent with the behavior seen in victims involved in sexual assaults, viz., the flight-and/or-fight response under crisis in the victim is impaired due to drug effects without impairment of mobility. This fact is scientific evidence supporting the conclusion that the behavior of victims, which has often been posited in criminal trials by the defense as evidence of agreement or consent is actually due to the effect of neurodepressive drugs.

The dose of triazolam $(0.01 \mathrm{mg} / \mathrm{kg})$ used in this study was extremely close to that in clinical use. Evidence of the anxiolytic effects of triazolam using the elevated plus-maze test has been reported by Nishino et al. [22]; however, the dose administered in that study was vastly higher than the dose used in clinical practice. Benzodiazepine receptor agonists generally cause anxiolytic effects at low concentrations, sequentially followed by muscle relaxation, sedation and hypnotic effects with increasing blood concentrations. Therefore, experiments using higher doses are unsuitable for evaluation of anxiolytic effects.

The results of this study clearly showed that animals under the influence of triazolam became insensitive to crisis or danger, even though they did not exhibit any reduction in activity levels. We confirm and assert that this finding is scientific evidence in rebuttal to implications of defense counsel arguments in trials that little or no evidence exists of the victim attempting to escape from the purported sexual assault. Additionally, the finding is as true of other benzodiazepine receptor agonists as of triazolam. The results of the present study provide concrete evidence for judicial authorities to adequately understand and recognize the behavioral and pharmacological effects of benzodiazepine receptor agonists. In other words, the avoidance of danger and lack of fight-and/or-flight responses to crisis, which are the natural instinct and response in humans and animals under normal circumstances to survive intact, is impaired by date-rape drugs, especially benzodiazepine receptor agonists. It will be useful if the present results could be used as reference material in the investigation and prosecution of DFSA cases, and in so doing this scientific evidence will contribute to the protection of the legal and human rights of victims.

\section{Conflict of Interest}

The authors declare that they have no conflict of interest. 
Citation: Shimizu K, Ohmura T, Okuda K, Asari K, Shiono H, Matsubara K (2016) Triazolam Impairs Avoidance Reaction-A Scientific Proof Why the Victim does not Escape from Drug-Facilitated Sexual Assaults. J Foren Psy 1: 108. doi:10.4172/2475-319X.1000108

Page 4 of 4

\section{Acknowledgements}

This study was supported by a Grant-in-aid for Scientific Research from the Ministry of Education, Science, Sports and Culture of Japan.

\section{References}

1. Shimizu K (2006) Date-rape drug and anterograde amnesia. Asahikawa Med Univ Res Bull 7: 2-12.

2. Hall JA, Moore CB (2008) Drug facilitated sexual assault - A review. J Forensic Legal Med 15: 291-297.

3. LeBeau MA, Mozayani A (2001) Drug-Facilitated Sexual Assault: A Forensic Handbook. California, Academic Press, USA.

4. US Dept. of Justice (2004) Drug-facilitated Sexual Assault Fast Facts.

5. US Dept. of Health \& Human Services (2012) Date rape drug fact sheet.

6. Monterey County Rape Crisis Center. Predator Drugs.

7. FBI - Club Drugs. US Dept. of Justice. Federal Bureau of Investigation. Tips for Parents: The Truth About Club Drugs.

8. National Institute on Drug Abuse (2014) Drug Fact: Club Drugs (GHB, Ketamine, and Rohypnol).

9. Fact about Date-Rape Drugs. Illinois Department of Public Health.

10. University of Notre Dame. The Office of Alcohol and Drug Education Date rape drugs: XTC, Rohypnol, Ketamine.

11. Brown University Health Promotion. What are date rape drugs?

12. Wikipedia, the free encyclopaedia. Date rape drug.

13. Date rape drugs. Medicinenet.

14. Kehner GB, Triggle DJ (2004) Date Rape Drugs (Drugs: the Straight Facts). New York, Chelsea House, USA.

15. May S, Triggle DJ (2011) Date Rape Drugs (Understanding Drugs). New York, Chelsea House, USA.

16. Is Rohypnol illegal in the United States? Rohypnol Fast Facts. National Drug Intelligence Center. Product No. 2003-L0559-020. US Dept. of Justice.
17. Shimizu K, Matsubara K, Uezono T, Shiono H (1998) Reduced dorsal hippocampal correlates glutamate release significantly with the spatial memory deficits produced by benzodiazepines and ethanol. Neuroscience 83: 701-706.

18. Pellow S, Chopin P, File SE, Briley M (1985) Validation of open : closed arm entries in an elevated plus-maze as a measure of anxiety in the rat. J Neurosci Methods 14: 149-167.

19. Dawson GR, Tricklebank MD (1995) Use of the elevate plus maze in the search for novel anxiolytic agents. Trends Pharmacol Sci 16: 33-36.

20. Walf AA, Frye CA (2007) The use of the elevated plus maze as an assay of anxiety-related behavior in rodents. Nature Protocols 2: 322-328.

21. Miyamoto Y, Yamada K, Noda Y, Mori H, Mishina M, et al. (2002) Lower Sensitivity to Stress and Altered Monoaminergic Neuronal Function in Mice Lacking the NMDA Receptor $\varepsilon 4$ Subunit. J Neurosci 22: 2335-2342.

22. Nishino T, Takeuchi T, Takechi K, Kamei C (2008) Evaluation of anxiolytic-like effects of some short-acting benzodiazepine hypnotics in mice. J Pharmacol Sci 107: 349-354.

23. Lister RG (1987) The use of a plus-maze to measure anxiety in the mouse. Psychopharmacology 92: 180-185.

24. Yamada K, Iida R, Miyamoto Y, Saito K, Sekikawa K, et al. (2000) Neurobehavioral alterations in mice with a targeted deletion of the tumor necrosis factor-alpha gene: implications for emotional behavior. J Neuroimmunol 111: 131-138.

25. Sharma AN, Elased KM, Garrett TL, Lucot JB (2010) Neurobehavioral deficits in db/db diabetic mice. Physiol Behav 101: 381-388.

26. Hazim AI, Ramanathan S, Parthasarathy S, Muzaimi M, Mansor SM (2014) Anxiolytic-like effects of mitragynine in the open-field and elevated plus-maze tests in rats. J Physiol Sci 64: 161-169.

27. Morris HH III, Estes ML (1987) Traveler's amnesia. Transient global amnesia secondary to triazolam. JAMA 258: 945-946.

28. Bixler EO, Kales A, Manfredi RL, Vgontzas AN, Tyson KL, et al. (1991) Next-day memory impairment with triazolam use. Lancet 337: 827-831.

29. Ohshima $\mathrm{T}$ (2005) Criminal injury case using vegetable juice intermixed with triazolam. J Clin Forensic Med 12: 212-213. 